\title{
Prevalence and distribution of osteoarthritis in a population from Georgian and early Victorian London
}

\author{
H A Waldron
}

\begin{abstract}
The prevalence of osteoarthritis was calculated in adult skeletons excavated from the crypt of Christ Church, Spitalfields in east London, which was used for burial between 1729 and 1869. Age and sex specific prevalences were also calculated for a subsample of the group for whom age and sex were accurately known from surviving coffin plates. Prevalences were slightly higher in men than in women, except for generalised osteoarthritis.

The principal sites affected were the acromioclavicular joints, the facet joints of the spine, and the hands. Osteoarthritis of the large joints was relatively uncommon; osteoarthritis of the hip occurred in 4/360 (1.1\%) of men and 10/346 $(2.9 \%)$ of women and of the knee in $3 / 360(0.8 \%)$ of men and 18/346 (5.2\%) of women. This last difference was statistically significant.

A comparison with modern data suggests that the prevalence of osteoarthritis at Spitalfields was lower than in the contemporary population, and some explanations for this apparent difference are considered.
\end{abstract}

Osteoarthritis is a disease of considerable antiquity and is by far the most common condition found in human skeletal remains. On this account it has been extensively studied ${ }^{1}$ but seldom with the use of epidemiological methods. Attention has generally been given to osteoarthritis in past populations with a view to using the distribution of the disease as a predictor of activity or of occupation, although in the population studied here, it was not useful in this respect. $^{2}$

Age specific prevalences of osteoarthritis do not seem to have been reported before in early populations but are of interest because if they are found to have differed markedly between groups in the past, or are different from those found in the contemporary population, this would suggest that environmental or genetic factors, which may be important causes of the disease, are also likely to have differed.

One serious difficulty in calculating age

St Mary's Hospital, Praed Street, London Archaeology, Grchaeology, London WC1H OPY $H$ A Waldron

Correspondence to: St Mary's Hospital Praed Street,

London W2 INY.

Accepted for publication 2 May 1990 of the skeletons were recovered from coffins which still had legible coffin plates in place so that the name, and date and age at death of the incumbent was known precisely. This information formed the basis of an epidemiological specific prevalences in early populations is the unreliability of the methods used to determine the age of the skeleton, and an importan study of osteoarthritis in which age and sex specific prevalences were calculated.

\section{Skeletal population}

The skeletons used in this study were all recovered from the crypt of Christ Church, Spitalfields in east London, which was used for burial between 1729 and 1869 . Nine hundred and sixty eight skeletons were recovered during excavations carried out between 1984 and $1986^{3}$; of these, coffin plates survived for $367(37 \cdot 9 \%)$. There were 360 men and 346 women in the total sample; the smaller coffin plate sample comprised 142 men and 144 women over the age of 25 .

\section{Methods}

The palaeopathological classification of osteoarthritis depends upon finding eburnation, new bone formation around the joint margins or on the surface of the joint, pitting on the joint surface, scoring on the joint surface, and deformation of the normal contour of the joint. ${ }^{4}$ The radiological changes are those which are seen in the living, but generally they add little to what can be seen with the naked eye. Eburnation is pathognomonic of osteoarthritis in palaeopathological terms but where it is absent, the presence of at least two of the other changes listed above is required before the condition can be classified; it would not be so classified on the finding of, for example, new bone around the joint margins alone (see Rogers et $a l^{4}$ for further details). In the great majority of cases here eburnation was present. Where it was not, a combination of new bone around the joint margin or on the joint surface and pitting on the joint surface was invariably used as the criterion for classification.

\section{Results}

\section{PREVALENCE OF OSTEOARTHRITIS}

Two hundred and fifty five skeletons (127 male, 117 female) had osteoarthritis at at least one site; sex was unknown in the remaining 11 cases. Thus the crude prevalences were $352 \cdot 8 / 10^{3}$ for men and $338 \cdot 2 / 10^{3}$ for women. Among the coffin plate group 49 men and 35 women had the disease and the age specific prevalences for this group are shown in table 1. The overall prevalence for the men in the coffin plate sample was almost identical with the crude prevalence for the total sample $(345 \cdot 1$ compared with $352 \cdot 8 / 10^{3}$ ), but the overall prevalence for the women in this group was much lower than 
the crude prevalence ( $243 \cdot 1$ compared with $\left.338 \cdot 2 / 10^{3}\right)$; this difference just reached significance $\left(\chi^{2}=3 \cdot 86, p=0 \cdot 048\right)$. It was substantially different from the prevalence found for women in the non-coffin plate sample $(82 / 202$, $\left.405 \cdot 9 / 10^{3}\right)$, and this difference was highly significant $\left(\chi^{2}=9 \cdot 25, \mathrm{p}<0.01\right)$.

\section{NUMBER OF SITES AFFECTED}

Among the 255 cases with osteoarthritis, a total of 483 sites was affected-mostly the shoulder, spine, hands, and feet (table 2). No major discrepancies were found between the distribution of affected joints in the coffin plate and the non-coffin plate samples.

In slightly under half the cases only a single joint was affected and in almost three quarters $(186 / 255,72.9 \%)$ two joints at most were involved. (For the purposes of this analysis the facet joints of the spine were regarded as a single entity no matter how many were affected.) Table 3 shows the male/female ratio for the different numbers of joints affected. Women tended to have more joints affected than men. This impression was confirmed when the categories were truncated, grouping together those with five or six joints affected, and a $\chi^{2}$ test for trend carried out; the trend was significant $\left(\chi^{2}=5 \cdot 73, p<0.05\right)$.

\section{COMBINATION OF SITES AFFECTED}

As might be expected there were many combinations of affected joints; table 4 shows the

Table 1 Prevalence of osteoarthritis by age and sex in the coffin plate sample

\begin{tabular}{lcc}
\hline Age & \multicolumn{2}{c}{ Prevalence $\left(\right.$ number $\left./ 10^{3}\right)$} \\
\cline { 2 - 3 } & Men & Women \\
\hline $25-$ & $66 \cdot 7$ & $71 \cdot 4$ \\
$45-$ & $350 \cdot 0$ & $200 \cdot 0$ \\
$65+$ & $500 \cdot 0$ & $360 \cdot 7$ \\
Total & $345 \cdot 1$ & $243 \cdot 1$ \\
\hline
\end{tabular}

Table 2 Total number of sites affected by osteoarthritis in coffin plate and non-coffin plate samples

\begin{tabular}{|c|c|c|c|c|}
\hline \multirow[t]{2}{*}{ Site } & \multicolumn{2}{|c|}{ Coffin plate sample } & \multicolumn{2}{|c|}{ Non-coffin plate sample } \\
\hline & $n$ & $\%$ & $n$ & $\%$ \\
\hline $\begin{array}{l}\text { Shoulder } \\
\text { Spine } \\
\text { Hands } \\
\text { Feet } \\
\text { Sternoclavicular joint } \\
\text { Knee } \\
\text { Hip } \\
\text { Temporomandibular joint } \\
\text { Elbow } \\
\text { Wrist } \\
\text { Others }\end{array}$ & $\begin{array}{r}47 \\
37 \\
27 \\
15 \\
9 \\
9 \\
5 \\
3 \\
2 \\
1 \\
0\end{array}$ & $\begin{array}{r}30 \cdot 5 \\
23 \cdot 9 \\
17 \cdot 5 \\
9 \cdot 7 \\
5 \cdot 8 \\
5 \cdot 8 \\
3 \cdot 2 \\
1.9 \\
1 \cdot 3 \\
0 \cdot 6 \\
0\end{array}$ & $\begin{array}{r}85 \\
69 \\
63 \\
39 \\
26 \\
13 \\
10 \\
8 \\
7 \\
6 \\
2\end{array}$ & $\begin{array}{r}25 \cdot 9 \\
21 \cdot 0 \\
19 \cdot 2 \\
11 \cdot 9 \\
7 \cdot 9 \\
4 \cdot 0 \\
3 \cdot 0 \\
2 \cdot 4 \\
2 \cdot 1 \\
1 \cdot 8 \\
0 \cdot 6\end{array}$ \\
\hline
\end{tabular}

Table 3 Number of joints affected by osteoarthritis

\begin{tabular}{lccccccc}
\hline \multicolumn{7}{c}{ Number of joints affected } \\
\cline { 2 - 8 } & 1 & 2 & 3 & 4 & 5 & 6 & Total \\
\hline Male & 69 & 31 & 17 & 8 & 2 & 0 & 127 \\
Female & 47 & 28 & 30 & 8 & 3 & 1 & 117 \\
Total* $^{*}$ & 125 & 61 & 47 & 16 & 5 & 1 & 255 \\
Male/female ratio $^{1.40}$ & 1.47 & 1.11 & 0.57 & 1.00 & 0.67 & 0 & 1.09 \\
\hline
\end{tabular}

*Note that the totals may include some skeletons for which sex was not known. combinations that occurred most commonly and for completeness shows the numbers of single joints with osteoarthritis. The hands, shoulder, and spine were affected in differing combinations in over 100 cases, but the combination of hands, spine, and shoulder was the most common of all, being found in 15 skeletons (fig 1). In all but one of these 15 the cervical spine was affected, sometimes with other areas of the spine; in the other cases only the lumbar spine showed evidence of osteoarthritis. To see whether the 14 subjects in whom the cervical spine was affected shared any features which were different from the remaining group with osteoarthritis a nested case-referent study was undertaken. For each case two referents were drawn at random from the group with osteoarthritis with no matching. There were more women among the cases than among the referents ( 10 of 14 compared with 16 of 28 ), but this difference was not statistically significant. There was no difference in the age at death of the controls and referents.

\section{INDIVIDUAL JOINTS}

Shoulder joints

The shoulder joint was most commonly affected by osteoarthritis in this population, though in

Table 4 Number of cases with same combination of joints affected

\begin{tabular}{ll}
\hline foint(s) & $\begin{array}{l}\text { Number of } \\
\text { cases }(>1)\end{array}$ \\
\hline Shoulder & 43 \\
Spine & 23 \\
Feet & 22 \\
Hands & 20 \\
Hands, spine, shoulder & 15 \\
Spine, shoulder & 10 \\
Hands, spine & 7 \\
Hands, shoulder & 7 \\
Shoulder, sternoclavicular joint & 7 \\
Sternoclavicular joint & 6 \\
Hip & 5 \\
Hands, feet & 5 \\
Knee & 4 \\
Spine, sternoclavicular joint & 3 \\
Spine, knee & 3 \\
Hands, spine, shoulder, sternoclavicular joint & 3 \\
Hands, spine, feet & 3 \\
Shoulder, feet & 3
\end{tabular}

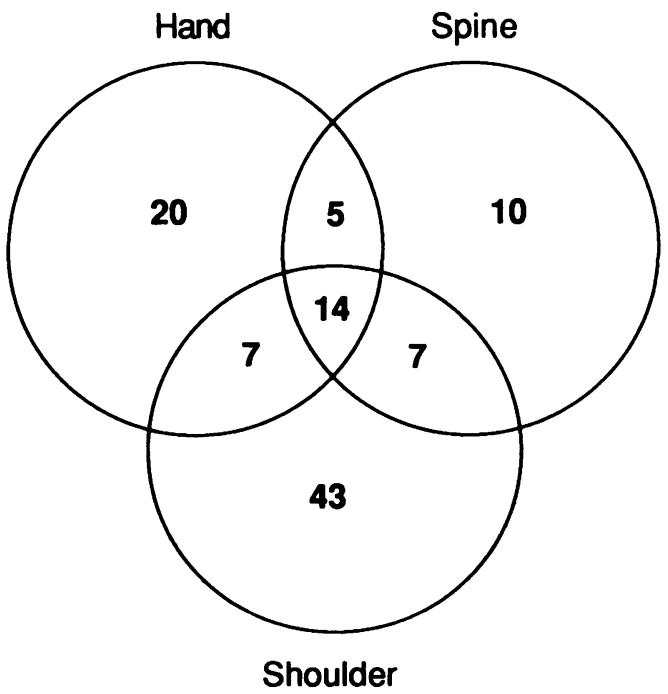

Figure 1 Relation between osteoarthritis of the hand, cervical spine, and shoulder. 
all but 15 cases only the acromioclavicular joint was affected. The male/female ratio was only slightly greater than unity $(1 \cdot 1: 1)$ and in most cases both acromioclavicular joints were affected; where only one was diseased this tended to be the right (table 5).

Five men and 10 women had osteoarthritis of the glenohumeral joint. In four men only the right was affected; in the fifth case the disease was bilateral. The women also showed preponderantly right sided osteoarthritis of the shoulder. In five of the 10 both joints were affected and in four cases the disease was present only on the right side.

Table 5 Number of men and women with osteoarthritis at major sites, by side affected

\begin{tabular}{|c|c|c|c|c|c|c|}
\hline \multirow[t]{2}{*}{ Foint } & \multicolumn{3}{|l|}{ Men } & \multicolumn{3}{|c|}{ Women } \\
\hline & Left & Right & Bilateral & Left & Right & Bilateral \\
\hline $\begin{array}{l}\text { Acromioclavicular } \\
\text { Sternoclavicular } \\
\text { Glenohumeral } \\
\text { Elbow } \\
\text { Wrist } \\
\text { Hip } \\
\text { Knee } \\
\text { Temporomandibular }\end{array}$ & $\begin{array}{l}5 \\
3 \\
0 \\
2 \\
1 \\
1 \\
0 \\
3\end{array}$ & $\begin{array}{l}9 \\
4 \\
4 \\
1 \\
1 \\
3 \\
2 \\
0\end{array}$ & $\begin{array}{r}45 \\
11 \\
1 \\
4 \\
2 \\
0 \\
1 \\
2\end{array}$ & $\begin{array}{l}3 \\
1 \\
1 \\
0 \\
3 \\
3 \\
1 \\
4 \\
2\end{array}$ & $\begin{array}{l}4 \\
5 \\
4 \\
0 \\
0 \\
6 \\
5 \\
2\end{array}$ & $\begin{array}{r}41 \\
11 \\
5 \\
2 \\
0 \\
3 \\
9 \\
2\end{array}$ \\
\hline
\end{tabular}

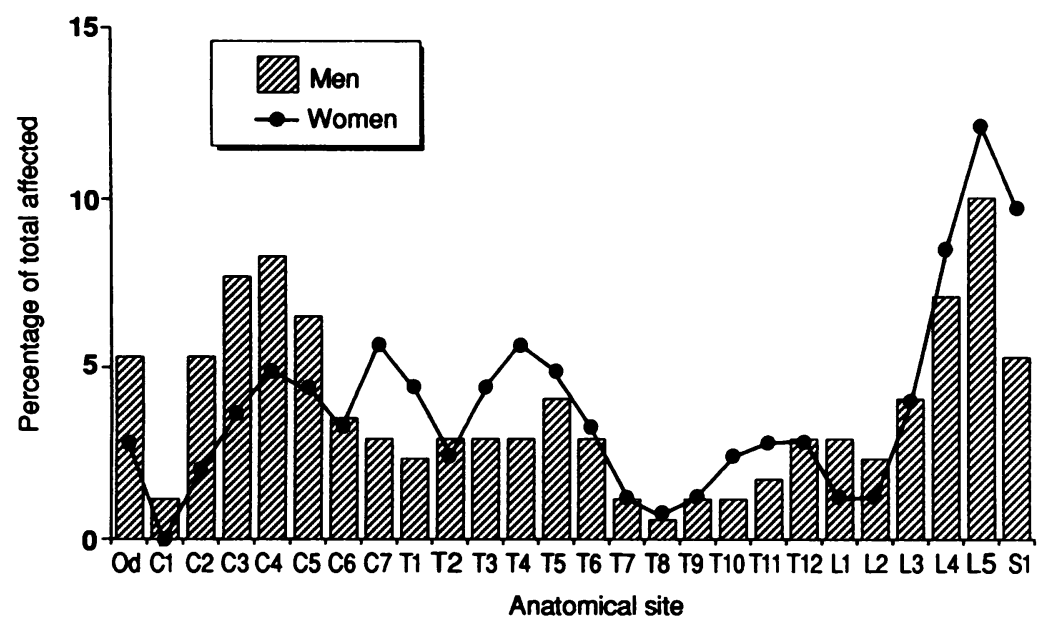

Figure 2 Anatomical sites of osteoarthritis of the spine in men and women.

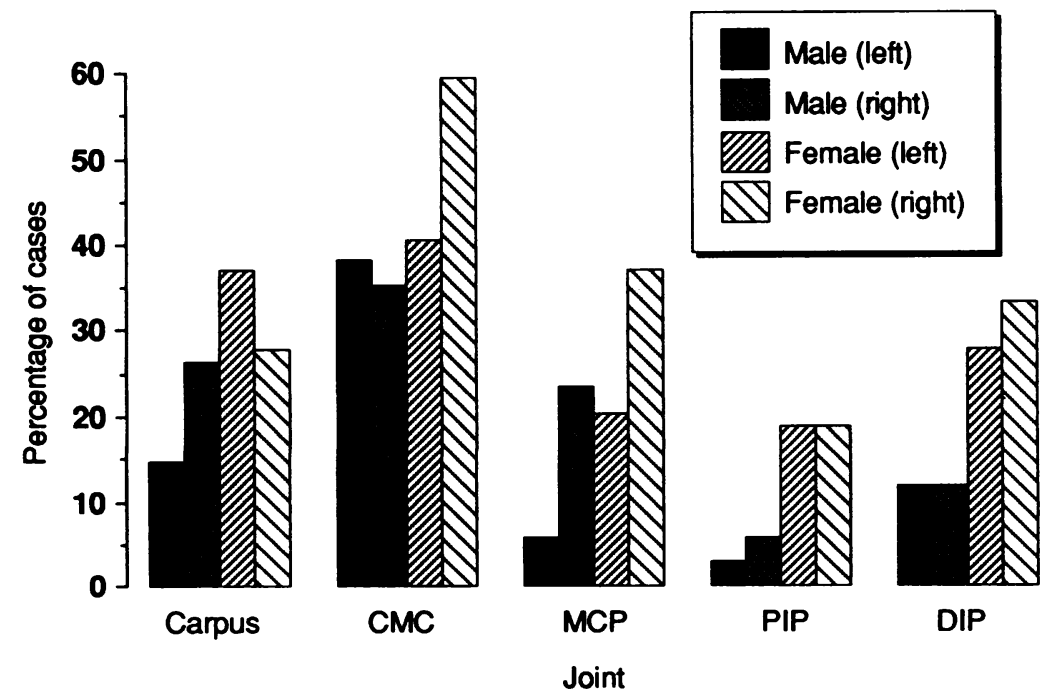

Figure 3 Anatomical sites of osteoarthritis of the hand in men and women, by side affected. $C M C=$ carpometacarpal joint; $M C P=$ metacarpophalangeal joint; $P I P=$ proximal interphalangeal joint; $D I P=$ distal interphalangeal joint.

\section{Sternoclavicular joints}

The sternoclavicular joints were arthritic in 18 men and 17 women. In most cases (11 men, 11 women) both joints were diseased, the left was affected singly in three men but in only one woman and the right joint was solely affected in four men and five women.

\section{The spine}

Figure 2 shows the distribution of osteoarthritis in the spine. One interesting feature was the number of occasions on which the disease affected the odontoid peg: seven cases in women and nine in men. Elsewhere, only the facet joints were affected, and there were some rather minor differences in the distribution of osteoarthritis at this site between the sexes. In women the disease was more widespread than in men and occurred relatively often throughout the cervical and upper thoracic spine, though the upper and lower articular processes of $\mathrm{Cl}$ were never affected. The lowest prevalence in the thoracic spine was at the level of T8; at lower levels of the spine it increased to reach a maximum at L5.

In men the mid-cervical spine (C2-C5) was more commonly affected than in the women, but the upper thoracic spine was less so. In the thoracic spine the minimum prevalence was noted at the level of T8 and in the lower reaches of the spine the prevalence increased to achieve its maximum at L5; this pattern closely mirrors that shown by the women.

\section{The hands}

Ninety cases (34 male, 54 female) had osteoarthritis of the hands; sex could not be determined in the two remaining cases. Figure 3 shows the distribution of the disease in the hands, from which it may be seen that there were some differences relating to sex and to side affected. In men the joints of the right carpus and the right metacarpophalangeal joints were more commonly affected than the left, and the carpometacarpal joints were most commonly affected of all. The proximal interphalangeal joints were scarcely affected at all and the distal interphalangeal joints in only four of the 34 cases (table 6).

In the women there was a right sided preponderance in the carpometacarpal, metacarpophalangeal, and distal interphalangeal joints; within the carpus the left joints were rather more often affected than the right. The finger joints were much more likely to be affected in

Table 6 Number (\%) of cases with osteoarthritis of the joints of the hand

\begin{tabular}{lrrlll}
\hline foint & \multicolumn{2}{l}{ Men $(n=34)$} & & \multicolumn{2}{l}{ Women $(n=54)$} \\
\cline { 2 - 3 } \cline { 6 - 6 } & \multicolumn{1}{c}{ Left } & Right & & Left & Right \\
\hline Carpus & $5(15)$ & $9(26)$ & & $20(37)$ & $15(28)$ \\
CMC* & $13(38)$ & $12(35)$ & & $22(41)$ & $32(59)$ \\
MCP* $^{*}$ & $2(6)$ & $8(24)$ & & $11(20)$ & $20(37)$ \\
PIP* $_{\text {DIP* }}$ & $1(3)$ & $2(6)$ & & $9(17)$ & $9(17)$ \\
& $4(12)$ & $4(12)$ & & $15(28)$ & $18(33)$ \\
\hline
\end{tabular}

* $\mathrm{CMC}=$ carpometacarpal; $\mathrm{MCP}=$ metacarpophalangeal; $\mathrm{PIP}=$ proximal interphalangeal; $\mathrm{DIP}=$ distal interphalangeal. 
women than in men; this was particularly so for the distal interphalangeal joints.

In both sexes the joints of the thumb and the thumb base showed the special predilection for osteoarthritis which is noted in present day clinical practice. Within the carpus the trapezium, trapezoid, and scaphoid were affected much more commonly than the other bones, and it was extremely unusual to find any carpometacarpal joint except the first affected by the disease. Of the metacarpophalangeal joints, the first was the most often affected by a considerable margin. The relative prevalence of the disease in the other metacarpophalangeal joints was $2>3>4>5$.

\section{Elbow joints}

Osteoarthritis of the elbows was found in only nine skeletons - seven male and two female. In the two female skeletons both elbows were diseased and this was also the case in four of the men; of the remaining three male skeletons, two had the left elbow affected and one the right.

In two of the male skeletons the arthritic changes seemed to have developed secondarily to a fracture in the proximal radius which had healed out of normal alignment.

\section{Wrist joints}

Seven cases (four male, three female) had osteoarthritis at the wrist joint. In each of the three female cases only the left wrist was affected. The disease was bilateral in two of the male cases and there was a single case affecting the left and the right wrists. In one of the female cases the disease was apparently secondary to a poorly healed radial fracture.

\section{Hip joints}

Osteoarthritis of the hip was uncommon in this series, affecting only 15 subjects in all-four male and 10 female; the sex was uncertain in the final case. The disease was unilateral in all the men, affecting the right side in three of the four. Unilateral disease was present in seven of the 10 women, on the right side in six. This difference in anatomical distribution was not statistically significant, nor was the difference in sex distribution.
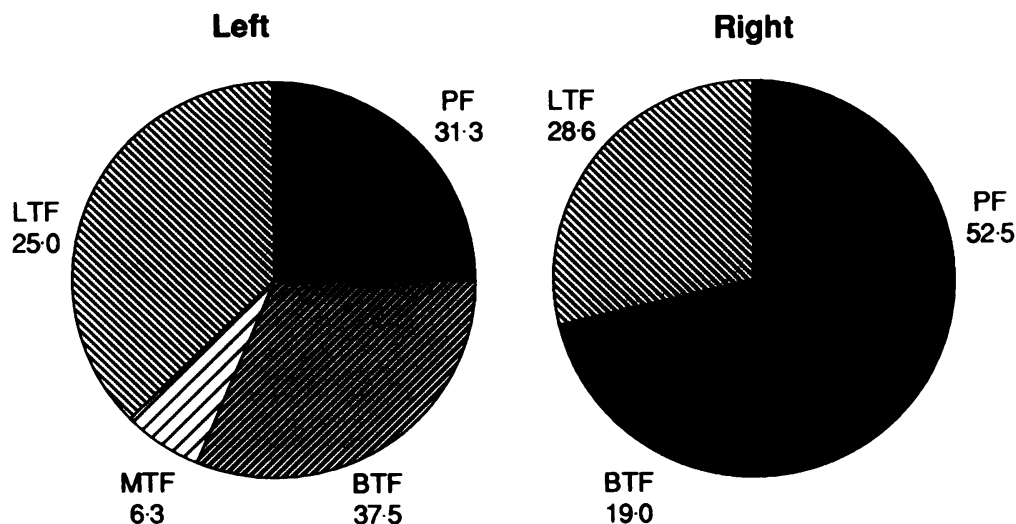

Figure 4 Percentage distribution of different sites affected by osteoarthritis of the knee, by side affected. $P F=$ patellofemoral compartment; $L T F=$ lateral tibiofemoral compartment $M T F=$ medial tibiofemoral compartment; $B T F=$ both tibiofemoral compartments.
Knee joints

Of the 22 cases with osteoarthritis of the knee, 18 were female and three were male; this difference was significant $(p<0.01)$. In the women the disease occurred bilaterally much more often than in the men; in nine cases compared with only one. In five of the nine women and in both men with unilateral disease the right side was affected.

Figure 4 shows the distribution of the disease among the different anatomical sites of the knee joint. On the left side the disease was more or less equally likely to affect the patellofemoral compartment, both tibiofemoral compartments together, or only the lateral. On the right side the patellofemoral compartment was affected in slightly more than half the cases. The medial tibiofemoral compartment was affected alone in one case only. These differences arose almost certainly by chance, however.

\section{Feet joints}

Fifty three skeletons had osteoarthritis of the feet and in all but three of these the disease affected the first metatarsals at the metatarsophalangeal joint. In the three other cases (all female) the tarsal bones were affected.

Of those with osteoarthritis of the metatarsals, 31 were male, 16 female (one who also had osteoarthritis at the tarsal joints), and the remaining six skeletons with the disease were of unknown sex. This sex difference was significant $\left(\chi^{2}=3.89, \mathrm{p}<0.05\right)$. There was no obvious predilection for one foot or another to be affected, however. Among the men both feet were affected in 12 cases, the left only was affected in 11 , and the right only in eight cases For the women the comparable numbers were five, seven, and three respectively.

\section{Temporomandibular joint}

Eleven of the skeletons (five male, six female) had osteoarthritis at the temporomandibular joints. The disease was evenly distributed in the women, two having bilateral disease and two each having unilateral disease affecting the left and right sides. Two of the men had bilateral disease, but in each of the remaining three only the left side was affected.

\section{GENERALISED OSTEOARTHRITIS}

Six cases (five women) had generalised osteoarthritis-that is, cases in which the distal interphalangeal joints, the thumb base, and the knee were affected. In none was less than five joints affected in total, most commonly the spine and shoulder in addition to those already mentioned (table 7). The crude prevalences for generalised osteoarthritis were $3 / 10^{3}$ in men and $14 / 10^{3}$ in women.

OSTEOARTHRITIS IN UNUSUAL SITES

Two cases were affected by osteoarthritis in unusual sites. In one, a skeleton of unknown age or sex, a false joint had formed between the left clavicle and the left first rib and the surfaces 
Table 7 foints affected in six cases with generalised osteoarthritis

\begin{tabular}{|c|c|c|c|c|c|c|c|c|c|}
\hline Sex (age) & $\underset{\text { joint }}{D I P^{*}}$ & $\begin{array}{l}\text { Thumb } \\
\text { base }\end{array}$ & Knee & Shoulder & Spine & Feet & $\begin{array}{l}S C^{*} \\
\text { joint }\end{array}$ & Elbow & $\underset{\text { joint }}{T M^{*}}$ \\
\hline $\begin{array}{l}\text { Male (88) } \\
\text { Female (77) } \\
\text { Female } \\
\text { Female } \\
\text { Female } \\
\text { Female }\end{array}$ & $\begin{array}{l}1 \\
1 \\
1 \\
1 \\
1 \\
1\end{array}$ & $\begin{array}{l}1 \\
1 \\
1 \\
1 \\
1 \\
1\end{array}$ & $\begin{array}{l}1 \\
1 \\
1 \\
1 \\
1 \\
1\end{array}$ & $\begin{array}{l}1 \\
1 \\
1 \\
1 \\
1 \\
1\end{array}$ & $\begin{array}{l}1 \\
1 \\
1 \\
1\end{array}$ & $\begin{array}{l}1 \\
1\end{array}$ & 1 & 1 & 1 \\
\hline Total & 6 & 6 & 6 & 6 & 4 & 2 & 1 & 1 & 1 \\
\hline
\end{tabular}

${ }^{*} \mathrm{DIP}=$ distal interphalangeal; $\mathrm{SC}=$ sternoclavicular; $\mathrm{TM}=$ temporomandibular.

of this joint were eburnated. There was no evidence of osteoarthritis elsewhere in this skeleton. The second case was an elderly woman with osteoarthritis of the shoulder, spine, and hands. The bases of both thumbs were affected, and so were the proximal interphalangeal and distal interphalangeal joints. In addition, the joint surfaces between the right third and fourth metacarpals were eburnated.

\section{OSTEOARTHRITIS IN YOUNG SUBJECTS}

Only two subjects with osteoarthritis were known to be less than 40 at the time of their death. One was a young women of 29 who had osteoarthritis at the base of her right first metacarpal. The osteoarthritis, however, had developed as the result of a deformity of the metacarpal such that the base was set at about $45^{\circ}$ to the shaft, most probably the legacy of a fracture. There was no evidence of disease elsewhere in the skeleton. The other subject was a man of 33 with osteoarthritis of the first left interphalangeal joint; the remainder of the skeleton was normal. There was no obvious explanation for his osteoarthritis. He had worked as a cheesemonger, but it is unlikely that his occupation was to blame for his arthritis.

\section{Discussion}

PREVALENCES

As with other skeletal populations recovered from archaeological sites osteoarthritis was found to be by far the most common patho-

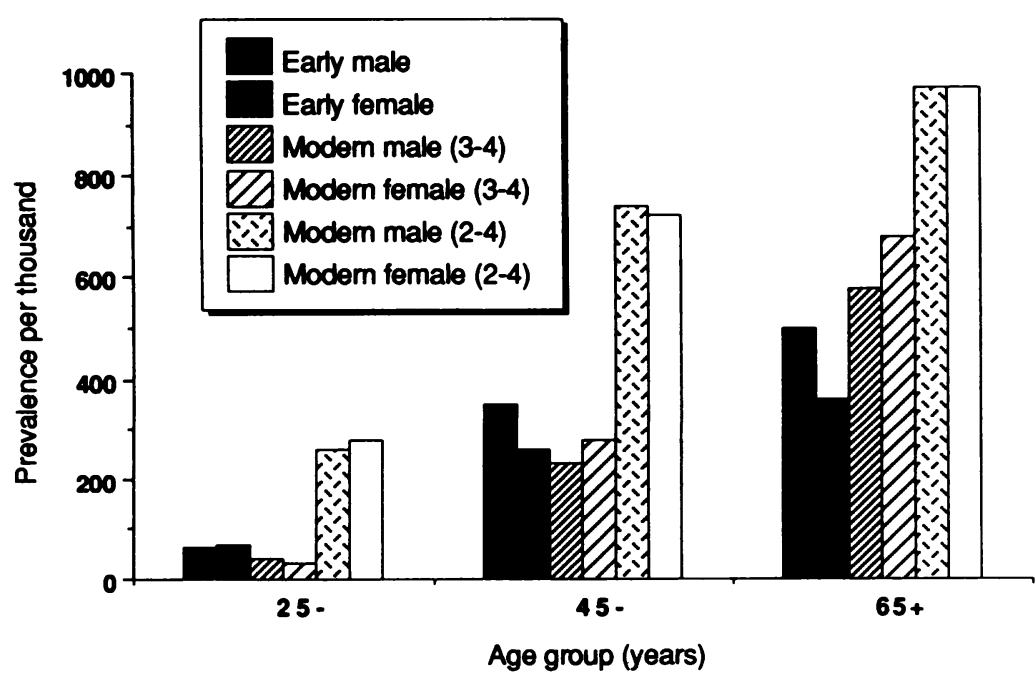

Figure 5 Comparison of prevalence of osteoarthritis in Spitalfields and a modern British population. Modern data taken from refs 5 and 6. Numbers shown in brackets refer to Lawrence's radiological categories. logical condition to affect the skeletons from Spitalfields. Having passed the age of 65 , half the men and slightly more than a third of the women had the condition in at least one joint, and in most cases the spine, acromioclavicular joints, or the hands were affected. It is difficult to compare these observations with those made on skeletal material from other sites because age standardised prevalences have generally not been calculated and the data presented by the other workers do not generally permit post hoc estimates to be derived; some preliminary work which we have undertaken, however, does indicate that prevalences did differ between populations in antiquity and that the prevalence with which different joints were affected was also subject to significant variation (Rogers and Waldron, unpublished data).

If there is little comparison which can be made with prevalences in other early populations, how do they compare with the prevalence in a modern British group? The most useful data in this respect are those from the now classic radiological studies conducted by Lawrence and his colleagues on a random population sample from the north of England. ${ }^{56}$ In comparing the Spitalfields' data with those of Lawrence, however, it is difficult to know which of his grades to use. Table 8 shows the prevalences for osteoarthritis from Lawrence's study of grades $2-4$ and 3-4 in at least one joint. Comparison of these data with the prevalences for the Spitalfields' population in table 1 (fig 5) shows that the latter are more like those of the higher severity in the modern population; they are much lower than the reported prevalences which include grade 2 disease.

A number of factors should be considered in this comparison, however. Firstly, the true prevalences in the Spitalfields' women might have been higher than they seem from this analysis; it will be remembered that the prevalence in those women for whom age and sex were known was significantly lower than in the other adult women, but no obvious explanation for this is apparent if chance is excluded. Secondly, there are no large series of published data which correlate radiological and palaeopathological classifications of osteoarthritis, though the work of Rogers and her colleagues suggests that, in the knee joint at least, large osteophytes and areas of eburnation, particularly in the patellar groove of the femur and on the anteroposterior aspects of the tibiofemoral joint, may be invisible on a radiograph, and hence radiologists classify less osteoarthritis than palaeopathologists. If these observations apply equally to other joints then this suggests that prevalences in skeletal material would tend to

Table 8 Prevalence of osteoarthritis in a modern population*

\begin{tabular}{|c|c|c|c|c|}
\hline \multirow{3}{*}{$\begin{array}{l}\text { Age } \\
\text { groupp }\end{array}$} & \multicolumn{4}{|c|}{ Prevalence (number/10 $0^{3}$ ) } \\
\hline & \multicolumn{2}{|l|}{ Men } & \multicolumn{2}{|l|}{ Women } \\
\hline & $\begin{array}{l}\text { Grades } \\
2-4\end{array}$ & $\begin{array}{l}\text { Grades } \\
3-4\end{array}$ & $\begin{array}{l}\text { Grades } \\
2-4\end{array}$ & $\begin{array}{l}\text { Grades } \\
3-4\end{array}$ \\
\hline $\begin{array}{l}25- \\
45- \\
65+\end{array}$ & $\begin{array}{l}258.9 \\
738.9 \\
969.5\end{array}$ & $\begin{array}{r}40 \cdot 4 \\
232 \cdot 4 \\
579 \cdot 3\end{array}$ & $\begin{array}{l}279 \cdot 2 \\
720 \cdot 6 \\
973 \cdot 2\end{array}$ & $\begin{array}{r}33 \cdot 0 \\
279 \cdot 4 \\
678 \cdot 6\end{array}$ \\
\hline
\end{tabular}

*Based on data in Lawrence, Bremner, and Bier ${ }^{5}$ 
be higher than in clinical or radiological series, not lower as found here.

The population at Spitalfields is, of course, not strictly comparable with that of a midtwentieth century English community. The Spitalfields group comprised a large proportion of Huguenots, and during the 18th century the area was prosperous; during the 19th century it declined in wealth and the number of unskilled workers increased considerably. Moreover, those who were buried in the crypt were probably more representative of the better off within the community. There is nothing in modern data, however, to suggest that social status is an important determinant of osteoarthritis and so far as we can tell occupational factors did not play a significant part in the cause of the disease at Spitalfields. ${ }^{2}$

A more general question must be asked, and that is, are prevalences which are calculated for a dead population a true reflection of those which prevailed in that population during life? An additional point to note is that skeletal populations almost always span a great deal of time, often three or four centuries and any prevalences calculated from them will mask any fluctuations which might have occurred throughout the period. There is, of course, nothing that the palaeopathologist can do about this except to note it with some regret and make the best of it. In this case the burials span about 140 years, and some of the earliest subjects buried in the crypt would have lived for several decades before it was opened; therefore, perhaps as much as $\mathbf{2 0 0}$ years' experience is represented here. There would be little to be gained from trying to arrange the prevalences over time (say in quarter centuries) as there would be so few subjects in each cell that the figures would have scarcely any validity.

But do the prevalences accurately reflect those of the living population from which these burials were derived? The answer-which will be considered in greater detail elsewhere-must surely be that they do. Osteoarthritis is not a disease which, in itself, leads to premature death, nor is it associated positively with other causes of death, so that subjects who have osteoarthritis may be expected to live their normal life span. There is thus no reason to expect that subjects with osteoarthritis will be either under- or overrepresented among a burial assemblage and prevalences should approximate to those in the living population.

These considerations lead me to suppose that the prevalence of osteoarthritis in this early population is indeed lower than in the modern population, though until more work has been carried out relating radiological and palaeopathological rates the precise degree to which they are lower must remain in some doubt.

\section{SITES OF OSTEOARTHRITIS}

At Spitalfields, as today, the most common sites for osteoarthritis are the facet joints of the spine, the distal and proximal interphalangeal joints, the joints around the thumb, the first ray of the foot, the hip, knee, and the acromioclavicular joints. ${ }^{8}$ Prevalences by site do not
Table 9 Rank order of osteoarthritis at different sites in early and modern populations

\begin{tabular}{lllll}
\hline $\begin{array}{l}\text { Rank } \\
\text { order }\end{array}$ & $\begin{array}{l}\text { Early } \\
\text { male }\end{array}$ & $\begin{array}{l}\text { Moderm } \\
\text { male }\end{array}$ & $\begin{array}{l}\text { Early } \\
\text { female }\end{array}$ & $\begin{array}{l}\text { Modern } \\
\text { female }\end{array}$ \\
\hline 1 & Spine & Knee & Spine & Feet \\
2 & Feet & DIPJ & CMCJ1 & DIPJ \\
3 & CMCJ1* & Feet & MCPJ & CMCJ1 \\
4 & MCPJ* $^{*}$ & Hip & DIPJ & Knee \\
5 & DIPJ* & Spine & Knee & PIPJ \\
6 & Hip & MCPJ & Feet & Spine \\
7 & Knee/PIPJ* & CMCJ1 & PIPJ & Hip \\
8 & Wrist & PIPJ & Hip & MCPJ \\
9 & Wrist & Wrist & Wrist \\
\hline
\end{tabular}

${ }^{*} \mathrm{CMCJ} 1$ = carpometacarpal joint, first ray; $\mathrm{MCPJ}=$ metacarpophalangeal joint; DIPJ = distal interphalangeal joint; PIPJ = proximal interphalangeal joint.

seem to be available for the age range at Spitalfields, but when the rank order of sites is compared with that in a modern group 910 the differences are slight (table 9); they are certainly not statistically significant.

In the Spitalfields' men osteoarthritis of the knee seems to be underrepresented and that of the spine more common than in modern men; in women the spine also seems to be more commonly affected than in their modern equivalents, but otherwise the distribution is relatively consistent. There are no comparative data for osteoarthritis of the acromioclavicular joint, which was extremely commonly affected at Spitalfields, but Resnick and Niwayama note that degenerative changes at this joint are almost universal in elderly subjects ${ }^{8}$; the findings at Spitalfields suggest that they would be seen commonly in younger subjects also were this joint to be examined radiologically more often. The same authors state that after the age of 50 or 60 all spines show the changes of the disease. Again, were the spines of younger subjects examined radiologically the findings would probably mirror those at Spitalfields.

One interesting feature in this series was the number of cases (16 in all) with osteoarthritis affecting the odontoid peg. It is by no means uncommon to find osteoarthritis at this site in skeletal material, but it is not discussed a great deal in clinical reports, perhaps because it may be asymptomatic. In a series of 31 patients described by Harata et al the disease most commonly affected the lateral atlantoaxial joints in addition to the atlanto-odontoid joint, which was affected singly in only five $(16 \%)$ cases. ${ }^{11}$ By contrast, there was only one case (a man of 66) with osteoarthritis of the lateral atlantoaxial joints in the Spitalfields group. Whether this is a true difference in prevalence which relates either to race or to some environmental factors, or whether it is a chance phenomenon, is difficult to say given the small numbers included. Further studies which are presently in hand and which include other large skeletal populations may provide the necessary information.

\section{AETIOLOGY OF OSTEOARTHRITIS}

One of the hopes of the Spitalfields project was that we would be able to correlate the distribution of osteoarthritis within the population with their occupation, which was known for many of those for whom we knew age and sex. As the 
predominant industry at Spitalfields during this time was weaving we have hoped that we might see changes in the hands such as those which Hadler and his colleagues have described. ${ }^{12}$ No positive correlation between weaving and osteoarthritis $^{2}$ was found, however, and there is little positive information about the cause of osteoarthritis in this group of subjects except that in eight cases the disease was secondary to other conditions, most commonly to fractures which had healed in poor alignment.

This study was part of a larger project which was funded by English Heritage, the Nuffield Foundation, and the Friends of Christ Church, Spitalfields, to whom all those who were engaged in this work owe a considerable debt of gratitude.

1 Rogers J, Watt I, Dieppe P. Arthritis in Saxon and medieval skeletons. BMF 1981: 283: 1668-71.

2 Waldron H A, Cox M. Occupational arthropathy: evidence from the past. Br $\mathcal{F}$ Ind Med 1989; 46: 420-2.
3 Adam M, Reeve J. Excavations at Christ Church, Spitalfields 1984-6. Antiquiry 1987; 61: 247-56.

4 Rogers J, Waldron T, Dieppe P, Watt I. Arthropathies in palaeopathology: the basis of classification according to most probable cause. Foumal of Archaeological Science 1987; 14: 179-93.

5 Lawrence J S, Bremner J M, Bier F. Osteoarthrosis. Prevalence in the population and relationship between symptoms and x-ray changes. Ann Rhewm Dis 1966; 25: symptom.

6 Lawrence J S. Rheumatism in populations. London: Heineman, 1977.

7 Rogers J, Watt I, Dieppe P. Comparison of visual and radiographic detection of bony changes at the knee joint. $B M$ F 1990; 300: 367-8.

8 Resnick D, Niwayama G. Diagnosis of bone and joint disorders. 2nd ed. Philadelphia: Saunders, 1988.

9 Kellgren J H, Lawrence J S. Osteoarthritis and disc degeneration in an urban population. Ann Rhewm Dis 1958; 17: 388-97.

10 Kelsey J L. Epidemiology of musculoskeletal disorders. New York: Oxford University Press, 1982.

11 Harata S, Tohno S, Kawagishi T. Osteoarthritis of the atlanto-axial joint. Int Orthop 1981; 5: 277-82.

12 Hadler N M Gillings D B, Imbus $H$, et al. Hand structure and function in an industrial setting. Influence of three patterns of stereotyped, repetitive usage. Arthritis Rheum
1978; 21: 210-20. 